\title{
Review of The Triumph of Numbers by I. B. Cohen
}

H L. Vacher

Department of Geology, University of South Florida, vacher@usf.edu

Follow this and additional works at: https://digitalcommons.usf.edu/numeracy

Part of the Mathematics Commons

\section{Recommended Citation}

Vacher, H L.. "Review of The Triumph of Numbers by I. B. Cohen." Numeracy 1, Iss. 1 (2008): Article 7. DOI: http://dx.doi.org/10.5038/1936-4660.1.1.7 


\title{
Review of The Triumph of Numbers by I. B. Cohen
}

\begin{abstract}
I. Bernard Cohen, The Triumph of Numbers: How Counting Shaped Modern Life. (New York: W.W. Norton \& Company, 2005). 209 pp. \$24.95 (USA). ISBN 0-393-05769-0.

The premier historian of science ends his career telling how the world has become awash in numbers-"how numbers entered the conduct of life and of government, the understanding of nature, and the analysis of societies." The stories begin with Kepler and end with Florence Nightingale. In between, major players include Galileo, Harvey, Leeuwenhoek, and Halley; Graunt and Petty; Jefferson and Franklin; Lavoisier, Sinclair, Pinel and Louis; Guerry and Quetelet. The book tells of the spread of what Cohen refers to as the "quantifying spirit" from physical science to "political arithmetic" (Sir William Petty), economics, and the beginning of psychiatry, sociology, medical statistics, and public health.
\end{abstract}

\section{Keywords}

history of science, history of numeracy, quantitative literacy

\section{Creative Commons License}

\section{c) (7) (8)}

This work is licensed under a Creative Commons Attribution-Noncommercial 4.0 License 
For sixty years, I. Bernard Cohen (1914-2003), one of the founders of the history of science department at Harvard ${ }^{1}$ and a leading scholar in his field, wrote definitive and multiple books on Franklin, ${ }^{2}$ Newton, ${ }^{3}$ the Scientific Revolution, ${ }^{4}$ early America, ${ }^{5}$ and more. He produced the first English translation of Newton's Principia since 1729 (with Latinist, Anne Whitman) - a 974-page translation that took 15 years to complete ${ }^{6}$. At the end of his life, he did us all the great service of writing about the context of quantitative literacy (although he did not use the term).

Cohen's last (posthumous) book, The Triumph of Number: How Counting Shaped Modern Life, is a must read for anyone interested in the subject of this journal. According to Peter Buck, who wrote the Foreword, the subtitle was not the author's. Cohen's original subtitle was How Numbers Entered the Conduct of Life and of Government, the Understanding of Nature, and the Analysis of Societies. That language easily makes the case for quantitative literacy (QL): How do we cope with a world where numbers have entered the conduct of life and government, our understanding of nature, and our analysis of societies? Cohen gives us the background: How did it come to be?

The Triumph of Numbers opens with a chapter called "A World of Numbers," a first section labeled "Numbers Everywhere," and a first sentence that makes the

\footnotetext{
${ }^{1}$ Harvard University Gazette. "History of science scholar I Bernard Cohen dies at 89: A Harvard man from undergraduate to emeritus." June 20, 2003. http://www.news.harvard.edu/gazette/ daily/0306/20-cohen.html.

${ }^{2}$ Benjamin Franklin's Experiments (Cambridge: Harvard, 1941); Benjamin Franklin: His Contribution to the American Tradition (Indianapolis: Bobbs-Merrill, 1953); Benjamin Franklin: Scientist and Statesman (New York: Scribner, 1975). Benjamin Franklin's Science (Cambridge: Harvard, 1990).

${ }^{3}$ Isaac Newton's Papers and Letters of in Natural Philosophy (Cambridge: Harvard, 1958); Isaac Newton's Theory of the Moon's Motion (Folkstone, Eng: Dawson, 1975); Newton: Texts, Backgrounds and Commentaries (New York: Norton, 1995).

${ }^{4}$ The Birth of a New Physics (Garden City: Anchor Books, 1960); The Newtonian Revolution (New York: Cambridge, 1980); Studies on William Harvey (New York: Arno Press, 1981); Revolution in Science (Cambridge: Harvard, 1985); Puritanism and the Rise of Modern Science: The Merton Thesis (New Brunswick: Rutgers, 1990).

${ }^{5}$ Some Early Tools of American Science (Cambridge: Harvard, 1950); Ethan Allen Hitchcock of Vermont: Soldier, Humanitarian and Scholar (Worchester MA: The Society, 1951); Aspects of Astronomy in America in the Nineteenth Century (New York: Arno Press, 1980); Thomas Jefferson and the Sciences (New York: Arno Press, 1980); Cotton Mather and American Science and Medicine (New York: Arno Press, 1980); Science and the Founding Fathers: Science in the Political Thought of Thomas Jefferson, Benjamin Franklin, John Adams, and James Madison (New York: Norton, 1995)

${ }^{6}$ William Cromrie. "Principia, Newton's greatest work, is newly translated." Harvard University Gazette, October 21, 1999. http://www.hno.harvard.edu/gazette/1999/10.21/newton.html
} 
familiar observation, "We live in a world of numbers." After "When did this invasion of numbers begin?" Cohen closes the first section with:

Although, over several centuries, enumerators collected numbers relating to such social phenomena as births, deaths, and marriages, no systematic analysis of these numbers occurred until well into the seventeenth century, the age of the Scientific Revolution.

Thus he brings the question to his unequaled expertise. The great story is to about to begin.

Before Kepler and Galileo, however, Cohen takes us on what Peter Buck calls a "detour." The meat of this first chapter concerns two illustrations about numbers in earlier history. First, there is the Great Pyramid: how quantitatively literate Napoleon estimated that there is enough stone in the Great Pyramid to build a wall of specified dimensions around France (I use this estimation problem in my course on QL in geology $y^{7}$ ), and how the vital statistics of the Pyramid have recently been used to reconstruct how those many huge stones were transported from the quarry to the site, and then up the ramp. Second, there is "Numbers in the Bible: The Sin of David." Why was it widely believed in the seventeenth century that it is sinful to make a census? That question and Napoleon segue to the time period of Cohen's main storyline.

Chapter 2, "New Worlds based on Numbers" is about the seventeenth century, the setting of the Scientific Revolution, and the spread of numbers-based thinking from the physical sciences to statistics, meaning the analysis of society. The main stories are:

- Kepler's harmonic law that the cube of a planet's average distance from the sun is proportional to the square of its period of revolution.

- Galileo's determination that the travel distance of a falling object is proportional to the square to the elapsed time.

- Harvey's argument that the capacity of the heart times the pulse rate implied a volumetric flow of blood too large for blood to be continuously produced by the liver (i.e., Galen).

- Leeuwenhoek's estimate of the number of people that the Earth can support in order that he could make the announcement that the number of "animalcula" in the milt of a cod (150 billion) is far larger.

- Halley's use of mortality tables fortuitously obtained from Silesia to develop principles of life annuities.

\footnotetext{
${ }^{7}$ Len Vacher. "How Large is the Great Pyramid of Giza?" Spreadsheets across the Curriculum. http://serc.carleton.edu/sp/ssac_home/general/ examples/14935.html
} 
- Graunt's analysis of London's Bills of Mortality-the first statistical analysis in recorded history-finding, among other things, that more males than females are born each year, and that London comprised 48,000 family units with 384,000 individuals.

- Petty's advocacy of a new form of statecraft, so-called political arithmetic, in which policy is based on numbers and measures, instead of "only comparative and superlative Words, and intellectual arguments" (Sir William Petty, Political Arithmetick, 1690, in Cohen, p. 58).

Chapter 3 is an appropriately short chapter on numerology, subtitled "Scientists at Play with Numbers." The first story is about schemes to identify "the Beast" numerically-mainly it was Martin Luther, but also the Pope. The second story concerns Huygens and Cassini and the number of moons of Saturn. The chapter closes with Pastor Caspar Neumann, who supplied the data for Halley's analysis. According to Pastor Neumann, the way to fight numerology is numerical data.

Chapter 4, the longest in the book, is about the eighteenth century, which ends of course with the American and French revolutions. The stories in "Numbers in the Age of Reason" are:

- The Scottish philosopher Francis Hutcheson and his attempt to quantify (1725) the morality of an action with $B=(M \pm I) / A$, where $B$ is the benevolence of the action; $M$ is the public good ("moment") produced by the action; $I$ is the private interest of the person; and $A$ is the person's natural ability.

- Hales' use of pressure gauges to learn of root pressure and thus the mechanism for sap to rise in the spring.

- Jefferson, and his findings from the numerical records of farming and gardening at Monticello; the numbers behind his belief that "a little rebellion, now and then, is a good thing, and as necessary in the political world as storms in the physical" (Jefferson 1787, in Cohen, p. 75); and the huge problem of apportionment, how to assign a fair number of representatives to states (a QL classic).

- Franklin and how he started his life with numbers by failing arithmetic twice in school; how he then taught himself accounting as a tradesman and shopkeeper; entertained himself with magic squares; and, stimulated by Petty's political arithmetic, developed a labor theory of value and published, in his Pennsylvania Gazette, all manner of numerical data on commerce and trade.

- Franklin's development of the concept of exponential population growth (acknowledged by Thomas Malthus in 1803), and how he used the concept 
to argue (1760) that Britain should annex Canada rather than Guadeloupe at the end of the French and Indian Wars so that British settlers would have room to grow and thus remain consumers of British production.

- Franklin's public advocacy of inoculation for smallpox, in which he presented data bearing on the probability of getting smallpox in an epidemic, the probability of dying from it, and the probability of dying from the lesser exposure to smallpox resulting from the inoculation.

In Chapter 5, "New Uses for Numbers," Cohen gives a too-short account of how the "quantifying spirit" (p. 95) in the eighteenth and early nineteenth centuries brought numerical methods into statecraft and medicine. Censuses replaced population estimates, for example, in numerous countries. Lavoisier's quantifying spirit not only led to quantitative experiments that revolutionized chemistry; it led him as a government official to determine the amount of land under cultivation and the number of horses and oxen employed in agriculture in France from data on the annual consumption of food, wine, and grain in urban and rural households and estimates of the population and various agricultural statistics. Sir John Sinclair, backed by the Church of Scotland, used questionnaires to every minister in the country to gather social and economic data for a 21-volume Statistical Account of Scotland. Philippe Pinel, the founder of psychiatry, attempted to put the treatment of mental disorders on a sound numerical basis by using a numerical method of classification and evaluation of success or failure. Pierre Charles Alexandre Louis, the "father of medical statistics" applied the "numerical method" with great success to the study of tubercoulosis and typhoid fever and demonstrated the ineffectiveness of the thenstandard practice of bloodletting - which was done by leeches - as a treatment for pneumonia and other diseases. Condorcet and Laplace advanced the theory of probability, but, strangely, Cohen does not elaborate "because our interest here is in numbers" (p. 112).

Chapter 6, "A Deluge of Statistics," on the early nineteenth century in France contains two sections. "Tables Galore" notes the accumulation of published numerical data on problems of statecraft and the human condition, particularly medicine, public health, marriages, births, deaths, and crime. "Guerry's Studies of Crime" tells of his large-format, chart-rich atlases of statistics of social pathologies, his finding that regions with the highest levels of education had the highest incidence of crime, his correlation of the means of a person's suicide with the person's age.

Chapter 7 is the climax of Cohen's story. He tells of "one of the most innovative and influential thinkers of the nineteenth century" (p. 124), Adolphe Quetelet and his "social physics." The chapter comprises six parts: 
- A tribute to the concept of an "average" man or woman (124) in the context of the 1933 decision to lift the ban on James Joyce's Ulysses in the U.S.

- The history of Quetelet, the mathematician and astronomer who invented the concept, his connection to Laplace, his prodigious correspondence, and his influence on the development of statistics.

- The meat of the chapter, "The Budget of Crimes"- the discovery of the regularity of the frequency of crime, the year-to-year constancy of the instruments used in manslaughter, the applicability of the error law to human variability.

His data indicated that 1 out of every 4,463 French persons ... would probably be accused of a crime, but no one could know in advance who that person would be. Evidently the new science of society would be unlike the science of Galileo and Newton. It would be based on statistical laws rather than simple deterministic laws (p. 130).

- Quetelet's caution about the accuracy of data and the soundness of analysis - a vital QL section.

- Quetelet's social physics vs. Auguste Compte's sociology as the name and concept for the scientific study of society.

- The recognition that statistics deals with more than matters of statecraft; it underpins social science and, with Maxwell and Boltzmann, it reached into natural science.

Chapter 8, "Critics of Statistics" features Charles Dickens' attacks on the emerging use of numbers. Dickens

opposed statistics on two grounds. He found that political leaders too often used statistics to block social legislation that would help the London poor and the factory workers. Additionally, statistics tended to concentrate on averages rather than individuals. Dickens saw himself as the spokesman for the individual and he took issue with the dehumanizing aspect of statistics that reduced human attributes to a set of impersonal numbers. (p.148)

This substantial chapter, with its details on the writings, is fascinating. It would make for useful discussion in a QL course.

Chapter 9, on Florence Nightingale, is an apt finale to follow the blasts from Dickens. Nightingale "believed that statistics could be used to improve the condition of humanity" (p. 172). Cohen tells of the nightmarish conditions she 
encountered at the British hospitals in the Crimea, and the sharp drop in the hospital death rate associated with the practices she implemented.

Neither the causes of disease, nor the way sanitation prevented it, were understood in the 1850s, but the evidence of the numbers was clear and indisputable. The health of British soldiers in hospitals depended on clean water and fresh air. Ergo, early Crimean mortality rates had been preventable...(p.164)

He describes her successful work, and use of statistics, to reform the sanitary conditions of the military in England when she returned; her interactions with Quetelet; her being the first woman to be elected into the Royal Statistical Society; her debilitating poor health after the Crimea. The chapter ends with the subject well known and appreciated by QL readers: her wonderful contribution to statistical graphics-the Nightingale coxcomb ${ }^{8}$. Nightingale, like Quetelet, believed that numbers should be accessible.

She thought that administrators, especially, should have (statistical) knowledge. Administrators are trained at universities, and therefore universities should teach statistics. (p. 176)

The epilogue closes the story at the turn of the twentieth century with the increasingly urgent need to handle repetitive calculations. Cohen notes Charles Babbage, who makes a cameo in the Nightingale chapter, and then segues to Herman Hollerith, a mining engineer who developed punch cards in 1890. Thus Cohen's story of numbers that entered the conduct of life and of government, the understanding of Nature, and the analysis of societies takes us up to "the brink of a new digital age of information" (p. 180).

Now we are deep into the digital age of information, of course. We have come to know the need for QL education, and we know that the expanding digital world offers potential to address that need. In this short, very readable, informative book, Cohen has provided us a great resource-an expert selection and historical ordering of stories that we can pursue through growing digital libraries and bring back to enrich our many and various classes. In time, our digital age of information may produce an educational Web site with links to samples of the original data behind these stories, and with problems that online QL students can work through to reconstruct their originators' arguments.

\footnotetext{
${ }^{8}$ E.g., Hugh Small. "Florence Nightingale's statistical diagrams." Florence Nightingale Museum, London. http://www.florence-nightingale.co.uk/small.htm
} 